\title{
Impact Analysis of the Change in Personal Injury Regulation in Albania
}

\section{Aranit Muja}

Faculty of Economics, University of Tirana

Doi: $10.2478 / \mathrm{mjss}-2018-0168$

\section{Abstract}

The regulation, no. 53, setting the compensation for motor third party bodily injuries in Albania is amended and has changed on July 1st, 2018. A significant increase in claims cost is expected, with direct consequences for insurers and policyholders. In order to estimate this change, we have conducted an analysis aiming to understand how the new amendment in the regulation would impact claim costs of personal injury. We start with a brief overview of the Insurance market in Albania. We then continue with some more technical data regarding the domestic MTPL, followed by some key highlights, and continue with an introduction of rules and procedures on handling claims covered by contracts of compulsory insurance in the transport sector in Albania. Finally we reveal how the capitalized amount coefficient is calculated and will analyze the impact of change in personal injury claims in the Albanian insurance market.

Keywords: MTPL, personal injury, annuity, capitalized amount coefficient

\section{Introduction}

In 2017 , compulsory motor insurance accounts for $67 \%$ of the Non-Life market with a premium volume of 9,964 million ALL and a growth of $4.82 \%$, compared to the previous year. The table below provides some data about the Domestic Motor Third Party Liability for the period 2013-2017. As shown in the table, both the volume of written premiums and the value of paid claims have increased during the period under consideration. The Combined and the Expense Ratio remain a concern. Regarding the Expense Ratio, it is set out in the Compulsory Motor Insurance draft law, which is expected to be approved soon, not to exceed $40 \%$. Almost the same indicators appear for the Green Card for which the Combined Ratio for the period under consideration is at $119 \%$. While Border Insurance demonstrates more satisfactory results, the Combined Ratio for the considered period is $77 \%$, but this product has an insignificant weight in the MTPL portfolio.

Table 1. Technical data (000 Lek/ALL). Source Albanian FSA.

\begin{tabular}{lccccc}
\hline DMTPL & $\mathbf{2 0 1 3 3}$ & $\mathbf{2 0 1 4}$ & $\mathbf{2 0 1 5}$ & $\mathbf{2 0 1 6}$ & $\mathbf{2 0 1 7}$ \\
\hline Gross written premiums & $2,743,835$ & $4,897,689$ & $6,607,202$ & $7,371,810$ & $7,807,969$ \\
Gross claims paid & $1,213,312$ & $1,153,270$ & $1,361,354$ & $1,682,100$ & $1,840,810$ \\
Net operating expenses & $\mathbf{1 , 8 6 6 , 4 5 8}$ & $\mathbf{2 , 2 6 6 , 8 0 8}$ & $\mathbf{3 , 0 3 3 , 1 8 9}$ & $\mathbf{3 , 8 2 1 , 2 6 4}$ & $\mathbf{4 , 3 4 6 , 7 8 0}$ \\
Net claims ratio & $58.41 \%$ & $37.37 \%$ & $29.71 \%$ & $33.66 \%$ & $27.89 \%$ \\
Expense ratio & $81.53 \%$ & $72.57 \%$ & $64.73 \%$ & $71.80 \%$ & $64.29 \%$ \\
Combined ratio & $139.95 \%$ & $109.94 \%$ & $94.44 \%$ & $105.46 \%$ & $92.18 \%$ \\
\hline
\end{tabular}

As is known and explained by Stéphane de Collasson, Motor Third Party Liabilities (MTPL) is a liability insurance, mandatory, guaranteeing that the insurer will indemnify the traffic losses, created 
by the person who caused the traffic accident, to the victim. Same definition applies in Albania as well. In this regard, MTPL insurance gives the policyholders the assurance that the damage created, will be covered and that the person who triggered the accident will not be entitled this coverage. On a contrary, compulsory MTPL insurance gives the victims sureness that the losses caused to them will be covered.

Some key highlights regarding domestic MTPL:

- The insurance undertaking determines the insurance premium tariffs and starts their application after it informs the AFSA.

- Minimum Amount of Insurance Coverage compared to some selected country:

Table 2. Minimum Amount of Insurance Coverage in selected country ${ }^{1}{ }^{2}$ (values in Euro).

\begin{tabular}{|c|c|c|c|c|c|c|}
\hline \multirow{2}{*}{ Country } & \multicolumn{3}{|c|}{ Personal injury } & \multicolumn{3}{|c|}{ Property damage } \\
\hline & a) & b) & c) & a) & b) & c) \\
\hline$\overline{A l b a}$ & 394,000 & $\begin{array}{ll}1,180,000 \\
\end{array}$ & $1,575,000$ & 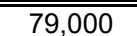 & $\overline{1118,000}$ & $\overline{157,000}$ \\
\hline Kosovo & $1,000,000$ & $2,000,000$ & 2,000 & 200 & 00 & 000 \\
\hline Montenegro & 550,000 & 00 & 800, & 300, & 00 & 550,000 \\
\hline Macedonia & 337,500 & 675,000 & $1,012,500$ & 168,750 & 337,500 & 506,250 \\
\hline Serbia & $1,000,000$ & $1,000,000$ & $1,000,000$ & 200,000 & 200,000 & 200,000 \\
\hline Croatia & $5,750,000$ & $5,750,000$ & $5,750,000$ & $1,150,430$ & $1,150,430$ & $1,150,430$ \\
\hline Italy & $5,000,000$ & $15,000,000$ & $15,000,000$ & $1,000,000$ & $1,000,000$ & $1,000,000$ \\
\hline
\end{tabular}

- The domestic MTPL risk is written to a single base tariff, with proportionate variations for different risk types (motorcycles are priced at a fixed discount to cars and trucks are priced at a fixed increase above cars).

- No other risk-based pricing is used - there is no price differentiation based upon age of driver/owner, location of owner, or of accident record ("no claims bonus").

- The claims frequency for Motor TPL business in Albania is low (around 3\%), if compared with the figures available in any other European country (usually more than $5 \%$ ).

By regulation, any person that suffered a damage as a result of vehicle accident in the Republic of Albania, shall be entitled to compensation for losses or damages, which consist of:

(a) proprietary damage:

i. personal injury resulting in death, temporary (partial or complete) and permanent (partial or complete) health injuries;

ii. material damage relate to the property damage or destruction.

(b) non-proprietary damage: biological damage; moral damage; existential damage.

Compensation for bodily injuries is a function of various parameters, such as: the age of the victim, the severity of the injury, the presence or not of relatives, the relationship of dependency between the victim and its relatives, income of the victim and income for own personal needs, duration of a potential hospitalization, retirement age.

\section{Change in the Personal/Bodily Injury Regulation in Albania}

In Albania, the law No. 10 076, February/2009, regulates compulsory insurance within the transport sector, but the rules and procedures for handling claims are guided by the Regulation no. 53. "On handling claims covered by contracts of compulsory insurance in the transport sector".

The liquidation technique normally used in the forensic practice is that of capitalization made

\footnotetext{
${ }^{1}$ where a)cars, b)buses and freight vehicles, including trailers and c) vehicles transporting hazardous substances

${ }^{2}$ Directive 2009/103/EC of the EU and the Council, as it was written on July $2^{\text {nd }} 2018$, stipulates the minimum allowed amount of cover which relates to the insurance on civil liability for the motor vehicles. For the Member States this amount is specified as follows: *The minimum amount of coverage is increased to EUR $1,050,000 / v i c t i m s$ or EUR 5,240,000/claim, no matter the number of victims; *The minimum amount of coverage for the material loss is increased to EUR 1,050,000/claim, no matter the number of victims
} 
on the basis of a coefficient for the establishment of a life annuity, commensurate with the duration of the residual future life of the injured party that can be predicted on the basis of statistical data. However, a corrective measure is necessary for taking into account the fact that the victim would not have received income for the whole life, but until the retirement age or in any case of withdrawal from the production cycle.

The capitalized amount coefficients that were used until 30th Jun 2018, were based on the coefficients published in Italy in 1922, which were obtained from the population census in the period 1901-1911. The coefficients were changed because:

- Other than referring to another country, average life expectancy has increased compared to 1922 ;

- The base interest rate of $4.5 \%$ is not constant anymore due to its reflection the country's economic environment.

- Reference was to common tables, not split into Women/Men, while statistics have shown that women's average life expectancy is always higher. formula:

By regulation, personal injury claims involving death shall be adjusted with the following

$$
D=\left(T_{a p}-K_{a v n p} \cdot T_{a p}\right) \cdot K_{s h k} \cdot K_{m d p}
$$

Where: $T_{a p}$ - annual personal income, $K_{a v n p}$ - income for own personal needs coefficient, $-K_{s h k}$ capitalized amount coefficient, $K_{m d p}$ - retirement age coefficient.

The recommendations in the regulation no. 53 , are as follows:

Regarding the annual personal income: - if the deceased was employed, the calculation is based on the average net income of the last three years prior to the day of the accident; - if the deceased was not employed, the calculation shall take into account the gross official minimum salary at the moment of the accident; - if the deceased was a private business owner, the calculation shall take into account the net income declaration as confirmed by the tax/social insurance authorities, and calculated as an average of the last three working years;

Regarding the income for own personal needs coefficient, it shall be calculated as follow: when the deceased had three or more persons (exclusive of the deceased) in his/her family, the deductible portion shall be $30 \%$ of the income; $40 \%$ if had two other persons and $50 \%$ if he/she had one other person in his or her family.

Regarding retirement age, the coefficient is fixed, if the deceased was employed, the retirement age coefficient is set to 0.90 and 0.8 if the deceased was unemployed.

\section{New Capitalized Amount Coefficients}

Following the publication of recent data by INSTAT (Albania: Population Projections 2011-2031), which is the latest information on mortality table in Albania, Albanian FSA updated the table in relation to the capitalized amount coefficients. The selected interest rate is $3.5 \%$, which is based on the average of the last 5 years of treasury bills with a maturity of 12 months and is in line with the return on investment of the assets covering the technical provisions.

The coefficients of the capitalized amount are based on two elements: - average future life expectancy of individuals, calculated taking into consideration mortality tables; - the interest rate used for capitalization. The higher the average life expectancy, the higher the capitalization coefficient, and the higher the interest rate to be taken into account, the lower the capitalization coefficient.

In the following paragraph we show how are calculated, from actuarial point of view, the capitalized amount coefficients. Based in:- International Actuarial Notation ${ }^{3}$, - (Pitacco E, 2000, 133), (Pitacco E, 2002, 202), (Rotar 2007, 502), Slud 2001, pages 1 and 149) and the other text books in actuarial mathematics, we have the mortality tables and commutation factors as follows:

- $q_{x}$, is the probability that $\mathrm{x}$ (age of a person) will die within 1 year, according to the mortality table

\footnotetext{
${ }^{3}$ Journal of the Institute of Actuaries (1886-1994), Vol. 75, No. 1 (JUNE 1949), pp. 121-129
} 
- $p_{x}$, is the probability that $\mathrm{x}$ will live up to $\mathrm{x}+1$, according to the mortality table

- $l_{x+1}=l_{x} \cdot\left(1-q_{x}\right)$, is the number of persons who attain age $\mathrm{x}+1$ according to the mortality table

- $d_{x}=l_{x} \cdot q_{x}$, the number of persons who die between ages $\mathrm{x}$ and $\mathrm{x}+1$ according to the mortality table.

- $v=\frac{1}{1+i}$, discounted factor, the present value of 1 due one year hence, according to the mortality table

- $D_{x}=v^{x} \cdot l_{x}$

- $N_{x}=\sum_{j=x}^{\omega} D_{j}$

- $\ddot{a}_{x}=\frac{N_{x}}{D_{x}}$, is an annuity-due to continue during the life of $(\mathrm{x})$, the first payment to be made at once.

- $\quad \alpha_{x}^{(k)}$, is an annuity of $\mathrm{x}$ payable by $\mathrm{k}$ instalments of $1 / \mathrm{k}$ each throughout the year, the first payment being one of $1 / k$ at the end of the first $1 / k$ th of a year.

- $\ddot{\alpha}_{x}^{(k)}$, is is an annuity-due where the first payment of $1 / k$ is to be made at once

$\alpha_{x}^{(k)}=\frac{k-1}{2 k} \ddot{\alpha}_{x}+\frac{k+1}{2 k} \alpha_{x}$

$\ddot{\alpha}_{x}=1+\alpha_{x}$

$\alpha_{x}^{(k)}=\frac{k-1}{2 k}+\alpha_{x}$

$\ddot{\alpha}_{x}^{(k)}=\ddot{\alpha}_{x}-\frac{k-1}{2 k}$

so, to calculate the capitalized amount coefficients, which is applied in (1), from $\ddot{a}_{x}$ we deduct by $11 / 24$ to express the payment monthly.

In order to see the difference between the coefficients that were in force up to 30th Jun, 2018 and the updated coefficients we consider three scenarios aiming at being representative of the diversity of potential situations. First scenario involve a 20 year old man/woman, unmarried with two surviving parents, second scenario involve a 40 year old man/woman, with one surviving spouse/husband and two children, and the third scenario involve a 55 year old man/woman with one surviving spouse/husband and two children. In the table 3 , below we calculate the compensation in case of death, for the three different scenarios. Based on the old coefficients the compensation was the same in case if the victim was male or female. With the new coefficients, ceteris paribus, there is a difference if the victim is male or female.

Table 3. Claim compensation for personal injury based on different scenarios (values in ALL).

\begin{tabular}{|c|c|c|c|}
\hline Data of the victim & $\begin{array}{c}\text { First scenario } \\
20 \text { year old, unmarried } \\
\text { with two surviving } \\
\text { parents } \\
\end{array}$ & $\begin{array}{c}\text { Second scenario } \\
40 \text { year old man, with one } \\
\text { surviving spouse/husband } \\
\text { and two children } \\
\end{array}$ & $\begin{array}{c}\text { Third scenario } \\
55 \text { year old man with one } \\
\text { surviving spouse/husband } \\
\text { and two children }\end{array}$ \\
\hline Monthly income & $\begin{array}{l}\text { Compensation } \\
\text { value(including the burial } \\
\text { expenses at a fixed amount } \\
\text { of } A L L 250,000 \text { ALL) }\end{array}$ & $\begin{array}{l}\text { Compensation value(including } \\
\text { the burial expenses at a fixed } \\
\text { amount of ALL } 250,000 \text { ALL) }\end{array}$ & $\begin{array}{c}\text { Compensation value } \\
\text { (including the burial expenses } \\
\text { at a fixed amount of ALL } \\
250,000 \mathrm{ALL} \text { ) }\end{array}$ \\
\hline \multicolumn{4}{|c|}{ Old coefficients } \\
\hline 200,000 ALL & $25,103,392$ & $24,922,816$ & $18,722,104$ \\
\hline $150,000 \mathrm{ALL}$ & $18,890,044$ & $18,754,612$ & $14,104,078$ \\
\hline $100,000 \mathrm{ALL}$ & $12,676,696$ & $12,586,408$ & $9,486,052$ \\
\hline 50,000 ALL & $6,463,348$ & $5,537,032$ & $4,868,026$ \\
\hline $\begin{array}{l}24,000 \text { ALL } \\
\text { (unemployed) }\end{array}$ & $3,232,407$ & $3,210,738$ & $2,220,358$ \\
\hline \multicolumn{4}{|c|}{ Updated coefficients } \\
\hline \multicolumn{4}{|l|}{ Man } \\
\hline 200,000 ALL & $32,036,412$ & $31,571,924$ & $24,601,129$ \\
\hline $150,000 \mathrm{ALL}$ & $24,089,809$ & $23,741,443$ & $18,513,347$ \\
\hline $100,000 \mathrm{ALL}$ & $16,143,206$ & $15,910,962$ & $12,425,565$ \\
\hline
\end{tabular}




\begin{tabular}{lccc}
\hline $\mathbf{5 0 , 0 0 0}$ ALL & $8,196,603$ & $8,080,481$ & $6,337,782$ \\
$\begin{array}{l}\mathbf{2 4 , 0 0 0} \text { ALL } \\
\text { (unemployed }\end{array}$ & $4,064,369$ & $4,008,631$ & $3,172,135$ \\
Woman & & & \\
$\mathbf{2 0 0 , 0 0 0}$ ALL & $33,004,944$ & $33,221,896$ & $26,655,143$ \\
$\mathbf{1 5 0 , 0 0 0}$ ALL & $24,816,208$ & $24,978,922$ & $20,053,858$ \\
$\mathbf{1 0 0 , 0 0 0}$ ALL & $16,627,472$ & $16,735,948$ & $13,452,572$ \\
$\mathbf{5 0 , 0 0 0}$ ALL & $8,438,736$ & $8,492,974$ & $6,851,286$ \\
24,000 ALL & $4,180,593$ & $4,206,628$ & $3,418,617$ \\
\hline
\end{tabular}

As we can see from the table, with the new updated coefficients, which are in force from July 1st, 2018, there is a significant increase in claim compensation. Based on the different scenarios presented in the table: a) if the victim is a male, there is in average an increase in claim compensation of: $-27 \%$ in the first scenario; $-28 \%$ in the second scenario; $-32 \%$ in the third scenario. b) if the victim is a female there is in average an increase in claim compensation of: $31 \%$ in the first scenario; - $35 \%$ in the second scenario; - $43 \%$ in the third scenario. As it is expected the increase for female is higher because statistics have shown that women's average life expectancy is always higher.

\section{Conclusion}

In this paper, firstly we have presented an overview of Albanian insurance market followed by some key highlights regarding Domestic MTPL. Then we have briefly presented the Regulation no. 53. "On handling claims covered by contracts of compulsory insurance in the transport sector". In the end we have presented the approach how capitalized amount coefficients are calculated, followed by a impact analysis of the change in personal injury regulation. We show, for three different scenarios, that with the new updated coefficients, which are in force from July 1st, 2018, there is a significant increase in claim compensation. The increase is more than $27 \%$ for male and more than $31 \%$ for female.

Regarding the Regulation no. 53, we recommend to amend the article 14, paragraph e) regarding the victims under 16 years, which by regulation receive a fixed compensation of ALL $1,000,000$. We believe that this compensation is discriminatory. One approach that we suggest to calculate the capitalized amount coefficients for victims under 16 years as follows:

capitalized amount coefficients of age $18 \cdot \frac{1}{(1+i)^{n}}$

where $i$ is interest rate used for each capitalized amount coefficients and $n$ is the difference of age 18 and the age of the victim at the moment of accident.

\section{References}

AON BENFIELD, Motor XL Market 2015, (2015).

Collasson, S.D., Impact analysis of the change in bodily injury regulation in Spain(2015).

Denuit, M., Mareshal, X., Pitrebois, S., Francois W.J.(2007). Actuarial Modelling of Claim Counts. John Wiley \& Sons, Ltd, England.

Klugman, S.,Panjer, H.,\&Willmot,G. (2004). Loss Models: From data to decisions. John Wiley \& Sons, Inc., New York.

Pitacco, E., Matematica e Tecnica Attuariale delle assicurazioni sulla durata di vita (2002). LINT Editoriale srl, Tieste.

Pitacco, E., Elementi di Matematica delle Assicurazioni (2000). LINT Editoriale srl, Tieste.

Rotar, V.I., Actuarial Models. The mathematics of Insurance (2007). Taylor \& Francis Group, LLC, NW.

Law no. 10 076, date 12.02.2009 "On compulsory insurance within the transport sector".

Regulation no. 53, date 25.06.2009 "On handling claims covered by contracts of compulsory insurance in the transport sector".

Annual Report 2017. http://amf.gov.al/publikime.asp?id=2 